\title{
Fusarium graminearum mycotoxins and their biosynthetic genes
}

\author{
Hokyoung Son and Yin-Won LEE* \\ Department of Agricultural Biotechnology and Center for Fungal Pathogenesis, Seoul National University, \\ Seoul 151-921, Republic of Korea
}

\begin{abstract}
Summary
The plant pathogenic fungus Fusarium graminearum (teleomorph: Gibberella zeae) is a crucial pathogen of major cereal crops and the fungus has taken on greater importance throughout the world. Taking advantage of rapid progress on fungal molecular techniques, we have studied biosynthetic pathways of harmful secondary metabolites of $F$. graminearum such as trichothecenes, zearalenone, and aurofusarin. We revealed that both Tri13 and Tri7 genes are requried for the chemotype determination of trichothecenes for nivalenol and 4 -acetyl-nivalenol production, respectively. We also constructed efficient chemotype determination system by utilizing distrupted Tri7 gene sequences of deoxinivalenol producers. Forward and reverse genetic approaches enabled us to characterize the gene clusters responsible for the biosynthesis of two polyketide compounds, zearalenone and aurofusarin. Both gene clusters cover genes encoding polyketide synthases and transcription activators. We also characterized an ABC transporter, ZRA 1, related with zearaleone production and constructed a zearalenone conditional gene expression system from the microarray analyses. These results increased our understanding on Fusarium genetics and mycotoxicology. Our future works will focus on revealing the regulatory mechanisms of toxin production and biological functions of these secondary metabolites.
\end{abstract}

Key words : Aurofusarin, Fusarium graminearum, Gibberella zeae, Trichothecenes, Zearalenone

(Received December 7, 2011)

\section{Text}

This proceeding paper summarizes our previous chemistry, genetics, and biology studies of cereal head blight fungus Fusarium graminearum. These studies were published in relating journals and increased our understanding on Fusarium genetics and mycotoxicology.

\footnotetext{
*Corresponding author.

Mailing address: Department of Agricultural Biotechnology and Center for Fungal Pathogenesis, Seoul National University, Seoul 151-921, Republic of Korea.

Phone: (+ 82) 2-880-4671.

Fax: (+82) 2-873-2317.

E-mail: lee2443@snu.ac.kr
} 


\section{A destructive cereal pathogen Fusarium graminearum in Republic of Korea}

The filamentous fungus Fusarium graminearum (teleomorph: Gibberella zeae) is a destructive cereal pathogen that causes Fusarium head blight (FHB) of major cereal crops, such as wheat, barley, and rice and Fusarium ear and stalk rot in maize throughout the world ${ }^{1}$. Plant disease caused by this fungus leads to not only severe yield losses but also accumulation of mycotoxins such as trichothecenes [nivalenol (NIV) and deoxynivalenol (DON)] and zearalenone (ZEA) in the infected cereals which poses grave threats to the health of animals and humans ${ }^{2}$.

An epidemic of FHB in Republic of Korea was firstly reported in 1963. The yield losses of cereals was about 80 to $100 \%$ in southern Korea, causing a serious social problem because of heavy economic losses and mycotoxicoses in humans and farm animals ${ }^{3}$. Subsequent FHB epidemics have been occurring about every 10 years and mycotoxin contaminations of cereals were continuously occurred in Korea ${ }^{4-8)}$. Recent toxin survey of Korean rice and its by-products revealed that they were highly contaminated with trichothecenes and ZEA ${ }^{9)}$. Recently, FHB on wheat is much more frequently occurring in southern part of Korea because of warm and humid weather during the flowering season.

Population distribution of F. graminearum was closely dependent on regional differences in Korea. O’Donnell et al $^{10)}$ described major F. graminearum clade as a lineage IV for Asia (Fig. 1 A). However, our in-depth population studies based on gene geneology in Korea revealed that northern part were predominant with lineage II, III, IV, and VII on corn samples and lineage VI and VII on rice samples. And lineage VI was mainly recovered from rice and barley samples from southern provinces ${ }^{11}$. Strains with NIV chemotype commonly found in most of the rice and barley samples but DON chemotype strains were predominant in maize of Gangwon province (Fig. 1B) ${ }^{4,8,12)}$.

A

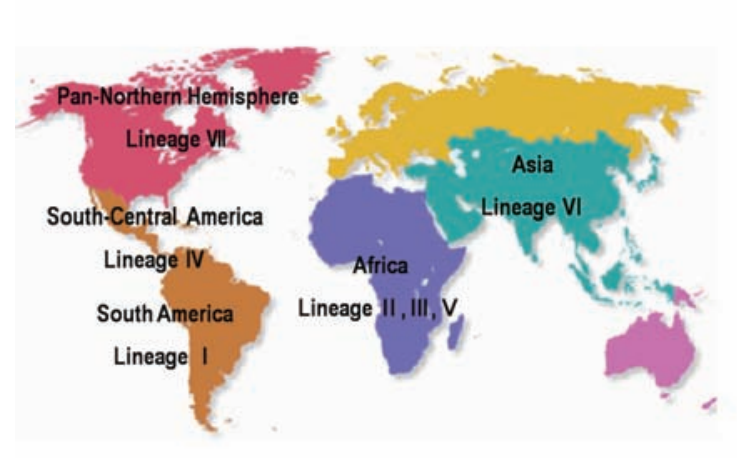

B

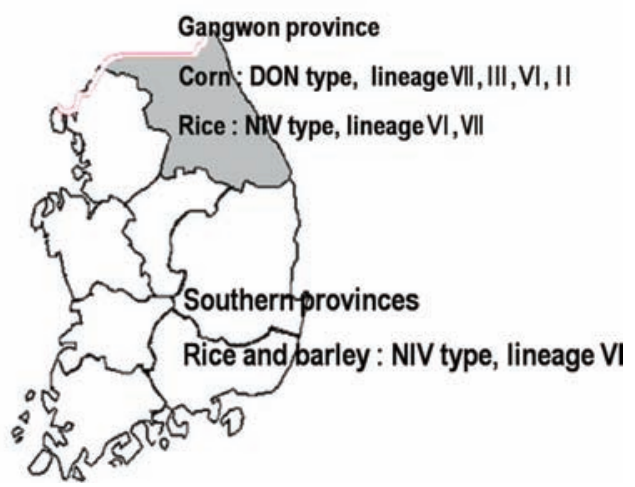

Fig. 1. Distributions of F. graminearum strains. (A) Phylogeographic structures of F. graminearum strains by gene geneology in the world based on previous phylogeographic study ${ }^{10)}$. (B) Population distribution of F. graminearum strains by gene geneology and amplified fragment length polymorphism (AFLP) of Korea ${ }^{11)}$. These figures were drown based on the previous reports ${ }^{10,11)}$ 


\section{Determination of trichothecene chemotypes}

Trichothecene contamination is known to be related with feed refusal, vomiting, diarrhea, dermatitis, and hemorrhages in farm animals ${ }^{13)}$. As mentioned above, F. graminearum strains are divided into two chemotaxonomic groups according to the production of 8-ketotrichothecenes (Fig. 2A). While DON chemotype strains

A

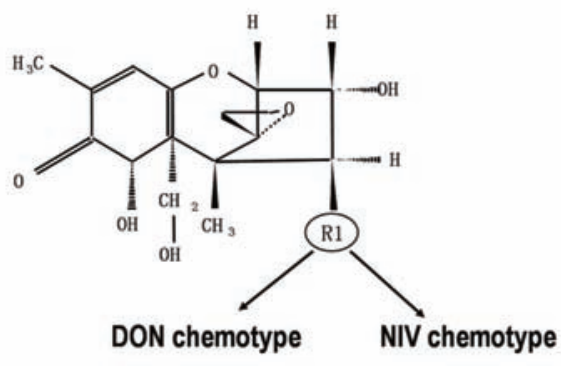

$\mathrm{H} \quad \mathrm{OH}$

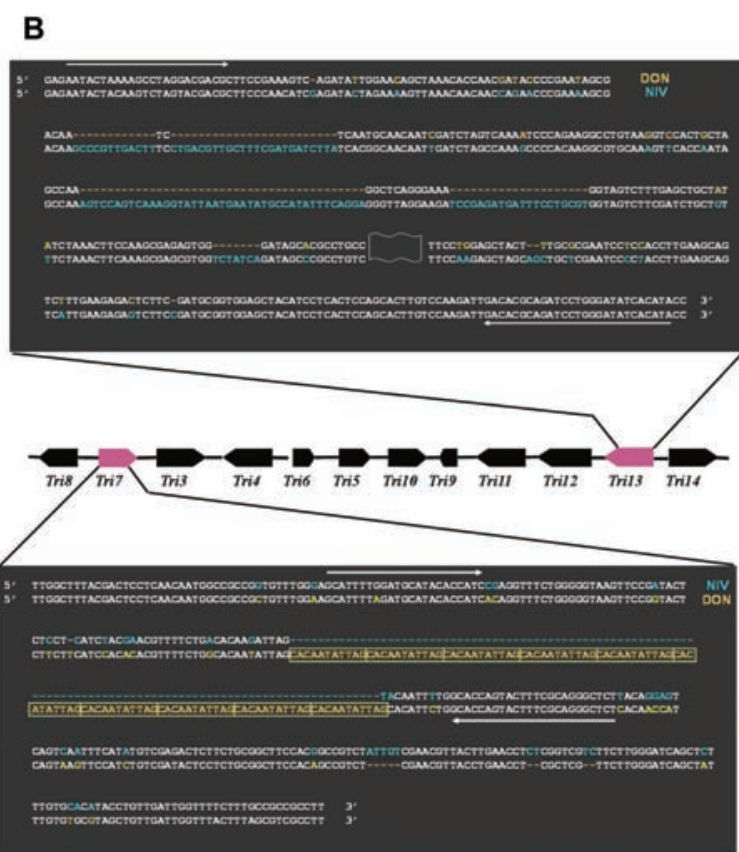

Fig. 2. Chemotype determination of F. graeminarum strains. (A) Chemical structure of trichothecenes. Functional groups of R 1 site of trichothecenes determine the chemotypes of $F$. graminearum strains. (B) Sequence variation of $\operatorname{Tr} i 7$ and Tri 13 between DON and NIV chemotype F. graminearum strains. Arrows mean the primers used for determination of chemotypes. The sequence comparisons were derived from the previous study ${ }^{19)}$. 
produce DON and acetyl-DONs such as 3-acetyl-DON (3-ADON) and 15-acetyl-DON (15-ADON), NIV and 4-acetyl-NIV (4-ANIV, also known as fusarenon-X) are produced by NIV chemotype strains ${ }^{14)}$. DON and NIV are the major 8-ketotrichothecenes found in Asian countries such as Korea and Japan and NIV is more frequently and highly present in cereals and exhibits greater toxicity than $\mathrm{DON}^{4,15-17)}$. Since the NIV chemotype is of great concern and both chemotypes existed in Korea, we tried to develop an easy and efficient system for differentiating DON and NIV chemotypes.

At least 10 genes required for trichothecene biosynthesis are localized in a gene cluster and their biochemical roles were intensively studied in F. sporotrichioides. Several homologs of these genes have been previously characterized in F. graminearum, and the recent study revealed that different Tri8 sequences determined whether Fusarium species produce $3-\mathrm{ADON}$ or $15-\mathrm{ADON}^{18)}$. At 2001 , we also built on the previous data of F. sporotrichioides to analyze the trichothecene biosynthesis gene clusters in the DON and NIV chemotypes of $F$. graminearum isolates ${ }^{19}$. We sequenced about $26-\mathrm{kb}$ gene cluster from both DON and NIV producers and found that gene cluster of F. graminearum from both chemotypes contained 10 Tri gene homologs in the same order and transcriptional directions as those of $F$. sporotrichioides (Fig. 2B). However, Tri7 and Tri13 sequences were variable between two chemotypes. Especially Tri7 gene open reading frame of DON producer carried several point mutations and insertion of tandem repeat sequences and the numbers of these repeats were different among the DON isolates. The primers which amplified this region of Tri7 could be easily used for F. graminearum chemotype determination (Fig. $2 \mathrm{~B})^{19)}$. Finally, we constructed an easy and efficient system for trichothecene chemotype determination in F. graeminarum using PCR.

Supposing that Tri7 and Tril3 were the genetic determinants of the DON and NIV chemotypes in F. graminearum based on our previous sequence data, further genetic study was performed to clarify the function of Tri7 and Tri13 genes in F. graminearum ${ }^{20)}$. Tri13 deletion mutant of NIV chemotype strain produced DON rather than NIV. And heterologous expression of Tri13 alone or both of Tri13 and Tri7 of DON strain in NIV producer resulted in altered trichothecene production (Fig. 3). The results suggested that Tri13 and Tri7 function for oxygenation and acetylation of the C-4 oxygen during NIV and 4-ANIV production in F. graminearum $^{20)}$.
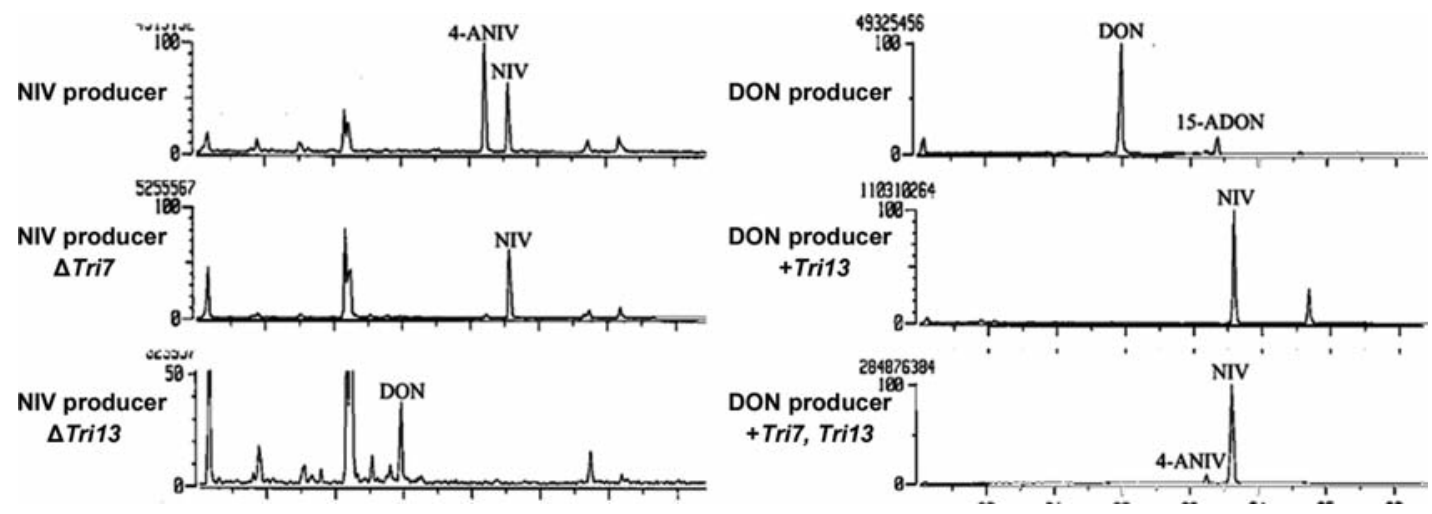

Fig. 3. Total ion chromatograms of extracts of $F$. graminearum cultures. Strains or deletion or heterologous expression of genes are listed in left side of each chromatogram. $\Delta$ Tri7, Tri7 deletion; $\Delta$ Tri13, Tri13 deletion; + Tri13, heterologous gene expression of Tri13 isolated from the NIV producer; + Tri7, Tri13, heterologous gene expression of both Tri7 and Tri13 isolated from the NIV producer. These chromatograms were derived from previous study with slight modifications ${ }^{20)}$. 


\section{Zearalenone biosynthesis and application of zearalenone for genetic studies}

Zearalenone [ZEA, 6-(10-hydroxy-6-oxo-trans-1-undecenyl)- $\beta$-resorcyclic acid lactone] is a wellknown polyketide metabolite produced by several Fusarium species ${ }^{13)}$. ZEA contaminations are associated with estrogenic disorders in swine and laboratory animals such as rats and mice ${ }^{21)}$. Together with trichothecene mycotoxins, ZEA was frequently occurred in cereal crops infected by F. graminearum and was also found in foodstuffs such as cornmeal, corn flakes, corn porridge, and beer ${ }^{13)}$. Recently, positive relationship between environmental ZEA or zearalenol (ZOL) exposures and the development of central precocious puberty in females was reported ${ }^{22)}$. However, the biological functions of ZEA in F. graminearum have not been characterized to date.

Previous chemical studies have proposed that ZEA is derived from acetate through the polyketide synthesis pathway $^{23)}$ and ZOL is a precursor for ZEA ${ }^{24)}$. Polyketide synthesis pathway is mediated by polyketide synthases (PKSs) and fungal type I PKSs are multifunctional proteins including all of the functional domain required for the formation of full-length polyketides ${ }^{25)}$. Complete genome sequencing of $F$. graminearum has allowed for genome-wide PKSs functional studies ${ }^{26,27)}$. We focused on non-reducing PKSs and firstly found that PKS13 and PKS4 were required for ZEA production ${ }^{28)}$. Other ZEA biosynthetic genes also are located in a gene cluster like trichothecene cluster genes (Fig. 4.). ZEB1 encoding isoamyl alcohol oxidase is required for conversion from ZOL to ZEA. ZEB2 is a transcriptional regulator and required for the activation of other cluster genes ${ }^{28)}$.

To investigate other genes involved in ZEA biosynthesis, we performed microarray analyses in ZEA-deficient and ZEA-enhanced conditions. ZEB2 deletion mutant was used for ZEA-deficient condition

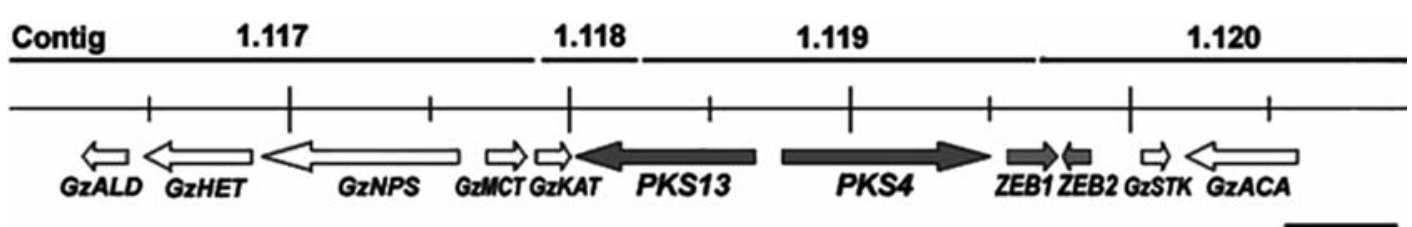

\begin{tabular}{|c|c|c|c|}
\hline Gene & Similarity & Species & E-value \\
\hline PKS13 & Polyketide synthase & Botryotinla fuckellana & 0.0 \\
\hline PKS4 & Polyketide synthase & Cochlibbolus heterostrophus & 0.0 \\
\hline ZEB1 & Isoamyl alcohol oxidase & Aspergillus oryzao & e-119 \\
\hline ZEB2 & Predicted protein ${ }^{\circ}$ & G. zeae & \\
\hline GZSTK & Protein kinase Eg2-like & Xenopus kevls & $8 e-80$ \\
\hline GZACA & $\mathrm{Ca}^{2}$ ATPase & Arabiogosis thalina & $0-171$ \\
\hline GZKAT & $\mathrm{K}^{+}$channel protein & A rabidopsis thalina & $4 e-75$ \\
\hline GZMCT & Monocarboxylate transporter like-protein & Aspergillus nidulans & $40-23$ \\
\hline GZNPS & Non-ribosomal peptide synthetase & Hypocrea virens & 0.0 \\
\hline $\begin{array}{l}\text { GZHET } \\
\text { GZALD }\end{array}$ & $\begin{array}{l}\text { Heterokaryon incompatibility protein } \\
\text { Aldehyde dehydrogenase }\end{array}$ & $\begin{array}{l}\text { Neurospora crassa } \\
\text { Zea mays }\end{array}$ & $\begin{array}{l}60-26 \\
e-104\end{array}$ \\
\hline
\end{tabular}

Fig. 4. Genetic organization of the $50 \mathrm{~kb}$ DNA region near PKS13. The arrow and arrowhead represent a putative gene and its transcriptional direction, respectively. Genes identified as required for ZEA biosynthesis in F. graminearum are indicated by filled arrows. Each DNA region of contigs in the F. graminearum genome databases is indicated by a thick bar with the contig number indicated above. Below table represents sequence similarities of the genes located at a cluster of $P K S$ genes. These figure and table were in the previous report ${ }^{28)}$. 
and starch-glutamate (SG) medium supplemented with ZEA was used for ZEA-enhanced condition ${ }^{28,29}$. In this study, we found a putative ABC transporter (ZRA1) which was under positive regulation of the ZEB2 gene and up-regulated in ZEA-enhanced condition. Although ZRA1 was not directly associated with ZEA export in F. graminearum, deletion and overexpression of ZRAl gene resulted in reduced and enhanced ZEA production, respectively (Fig. 5 A). However, localization of ZRA1 in plasma membrane and vacuoles still indicated possible roles of ZRA1 as a transporter (Fig. 5B).

Owing to the advanced molecular techniques such as targeted gene deletion, overexpression, and gene fusion to green fluorescent protein (GFP), many molecular studies have been performed to uncover the mechanisms related to pathogenicity, toxin production, and sexual development in F. graminearum. However, a conditional gene expression system for the studies of essential genes or heterologous gene expression was

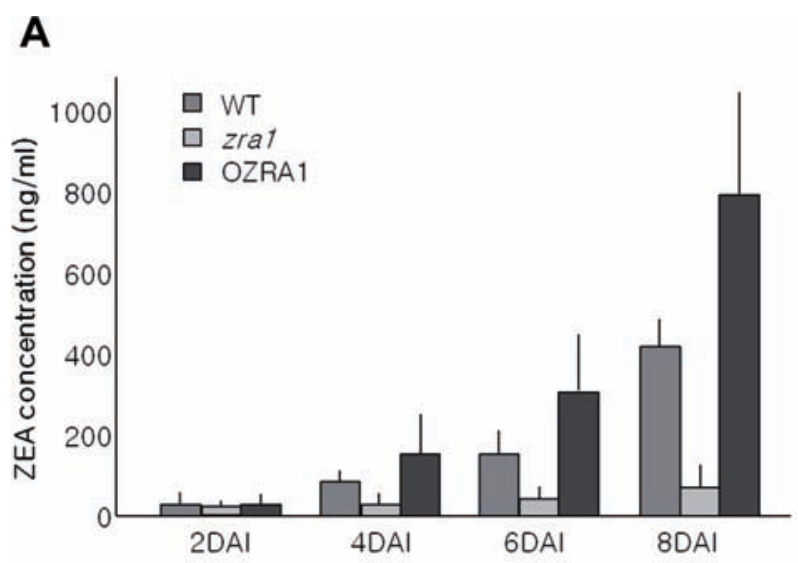

B
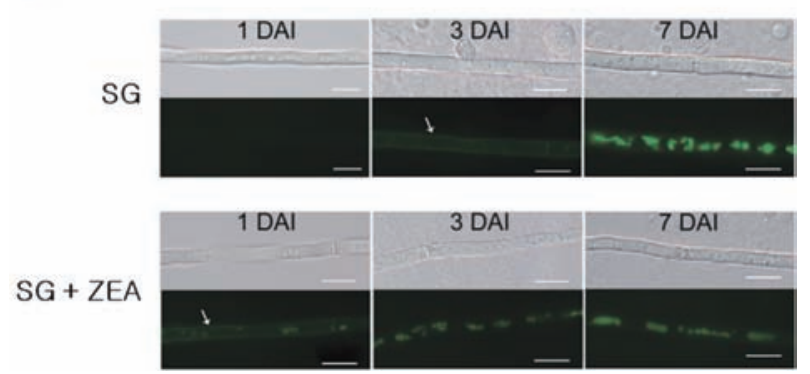

Fig. 5. ZEA production of ZRA1 mutants and localization of ZRA 1 -GFP. (A) ZEA production in wild-type, ZRAl deletion mutant, and ZRAl overexpression mutant strains. ZEA was extracted from culture filtrates of starch-glutamate (SG) liquid medium. (B) Cellular localization and expression of ZRA1-GFP in hyphae from SG liquid medium. Sampling time (day after inoculation) is indicated on the top. Arrows indicate plasma membrane localized ZRA 1 -GFP. Scale bars $=10 \mu \mathrm{m}$. WT, wild-type strain GZ3639; zra1, transgenic GZ3639 strain with ZRA1 deletion; OZRA1, ZRA1 overexpressed strain DAI, days after inoculation. These data were from the previous study on ZRAl gene with slight modifications ${ }^{29)}$. 
not available in this fungus. In the previous microarray data ${ }^{29)}$, we additionally got a new insight for genetic manipulation study ${ }^{30}$. We isolated a zearalenone response gene (ZEAR) which was highly expressed after ZEA treatment in microarray of ZEA-enhanced condition. ZEAR transcripts were dramatically increased after $1 \mathrm{~h}$ of ZEA treatment and that was dependent on ZEA concentration (Fig. 6A). When GFP was fused with promoter of ZEAR (Pzear), ZEA concentration-dependent increase in GFP expression was shown (Fig. 6B). We also confirmed that this inducible promoter system was applicable in other Fusarium species including $F$. oxysporum and $F$. verticillioides ${ }^{30)}$. This was the first report of an inducible promoter in F. graminearum and our recent genetic study actually utilized this conditional gene expression system to prove the lethality of gene deletion $^{31}$.

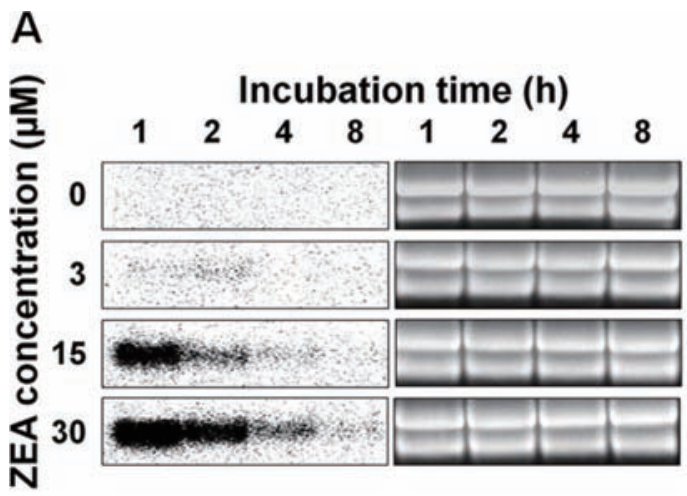

B

0

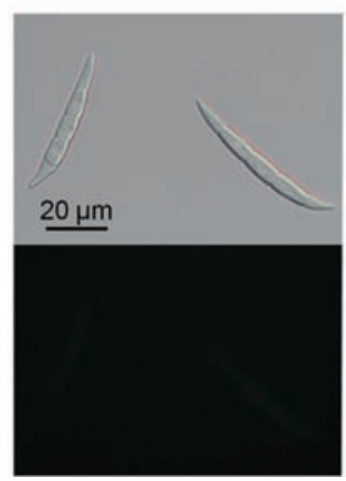

$15 \mu \mathrm{M}$ ZEA

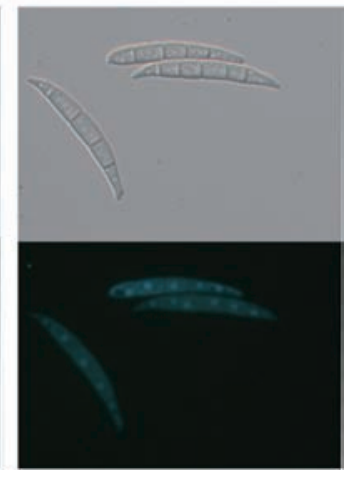

Fig. 6. Inducible expression of Pzear with ZEA treatment. (A) Analysis of ZEAR mRNA expression level. Total RNA of the F. graminearum wild-type strain was extracted from complete medium (CM) cultures grown for $1,2,4$, and $8 \mathrm{~h}$ after ZEA treatment. An ethidium-bromide-stained gel is shown as a loading control. (B) Pzear-GFP expression. Conidia were incubated for $1 \mathrm{~h}$ in $\mathrm{CM}$ supplemented with ZEA. These data were come from the previous report with slight modifications ${ }^{30)}$. 


\section{Revealing aurofusarin biosynthetic pathway}

Aurofusarin and rubrofusarin are PKS compounds and responsible for golden yellow and red color of fungal cultures of $F$. graminearum and F. culmorum $^{32,33)}$. Aurofusarin is a dimeric naphthoquinone which is toxic to poultry and frequently found in Fusarium infected crops ${ }^{34,35)}$. In addition, rubrofusarin is known to have antimycobacterial and antiallergic activities and this compound is phytotoxic to some weeds ${ }^{36-38)}$.

We have tried several forward genetic approaches to reveal the biological studies of F. graminearum during last 10 years. Restriction enzyme-mediated integration (REMI) mutagenesis was the most successful and we previously generated about 35,000 REMI transformants of F. graminearum. We further characterized genes related to vegetative growth, asexual and sexual reproduction, toxin production, and virulence ${ }^{39-47)}$. Among them, we found a laccase gene (GIP1) disrupted REMI mutant which was defected in red pigment production $^{47)}$. GIP1 gene was located in a gene cluster which includes 30-kb region and 10 genes. We additionally identified a gene encoding fungal type I PKS (PKS12) in the gene cluster and found that both GIP1 and PKS12 is required for aurofusarin biosynthesis in F. graminearum (Fig. 7A) ${ }^{47}$.

One of the cluster genes (GIP2) encoded putative transcription factor that carries $\mathrm{Zn}(\mathrm{II})_{2} \mathrm{Cys}_{6}$ binuclear cluster DNA-binding domain commonly found in transcription factors of fungal species (Fig. 7A). Deletion, complementation, and overexpression of GIP2 gene demonstrated that this transcriptional factor is a key regulator for aurofusarin biosynthesis. Similar with ZEB2 transcription factor in zearalenone biosynthesis, GIP2 also closely involved in activation of other genes in an aurofusarin biosynthetic gene cluster ${ }^{48)}$. We also suggested that aurofusarin production is negatively correlated with vegetative growth and ZEA biosynthetic pathway is negatively regulated by the accumulation of aurofusarin in this fungus ${ }^{49}$.

For better understanding on aurofusarin biosynthesis, we deleted all of the aurofusarin cluster genes and revealed that GIP7, GIP8, and GIP3 are additionally required for the completion of aurofusarin production in F. graminearum ${ }^{50,51)}$. Further in-depth biochemical study performed by Frandsen et al. ${ }^{52)}$ revealed that a new compound YWA1 is produced during an aurofusarin biosynthetic pathway and GIP6 /AurZ is required for transition from YWA1 to nor-rubrofusarin ${ }^{52)}$. And Frandsen et al. ${ }^{52)}$ additionally characterized AurS is a member of extracellular enzyme complex with GIP1, AurF/GIP8, and AurO/GIP3.

\section{Conclusion and future works}

Since Fusarium mycotoxins pose a great health treats to humans and animals and they are frequently detected in major cereals worldwide, continuous efforts for reducing the mycotoxin contamination are necessary. We have been revealed the biosynthetic pathways of ZEA, trichothecenes, and aurofusarin in head blight fungus F. graminearum. Our comprehensive results on mycotoxins have increased our understanding on Fusarium genetics and mycotoxicology. However, regulatory mechanisms of toxin production and biological functions of these secondary metabolites were rarely known to date and our future works will focus on these topics.

These works were supported by a grant (CG 1141 ) from the Crop Functional Genomics Center of the 21st Century Frontier Research Program funded by the Korean Ministry of Education, Science, and Technology and by a National Research Foundation of Korea (NRF) grant (2011-0000963) funded by the 
A

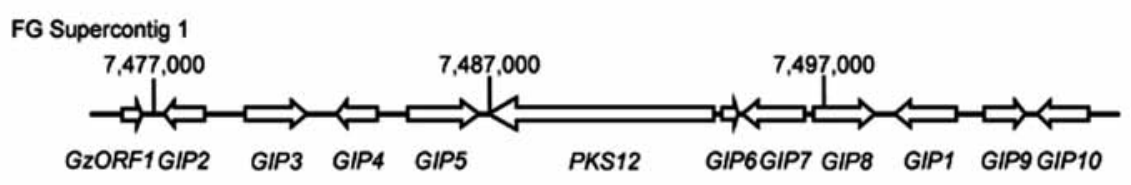

B
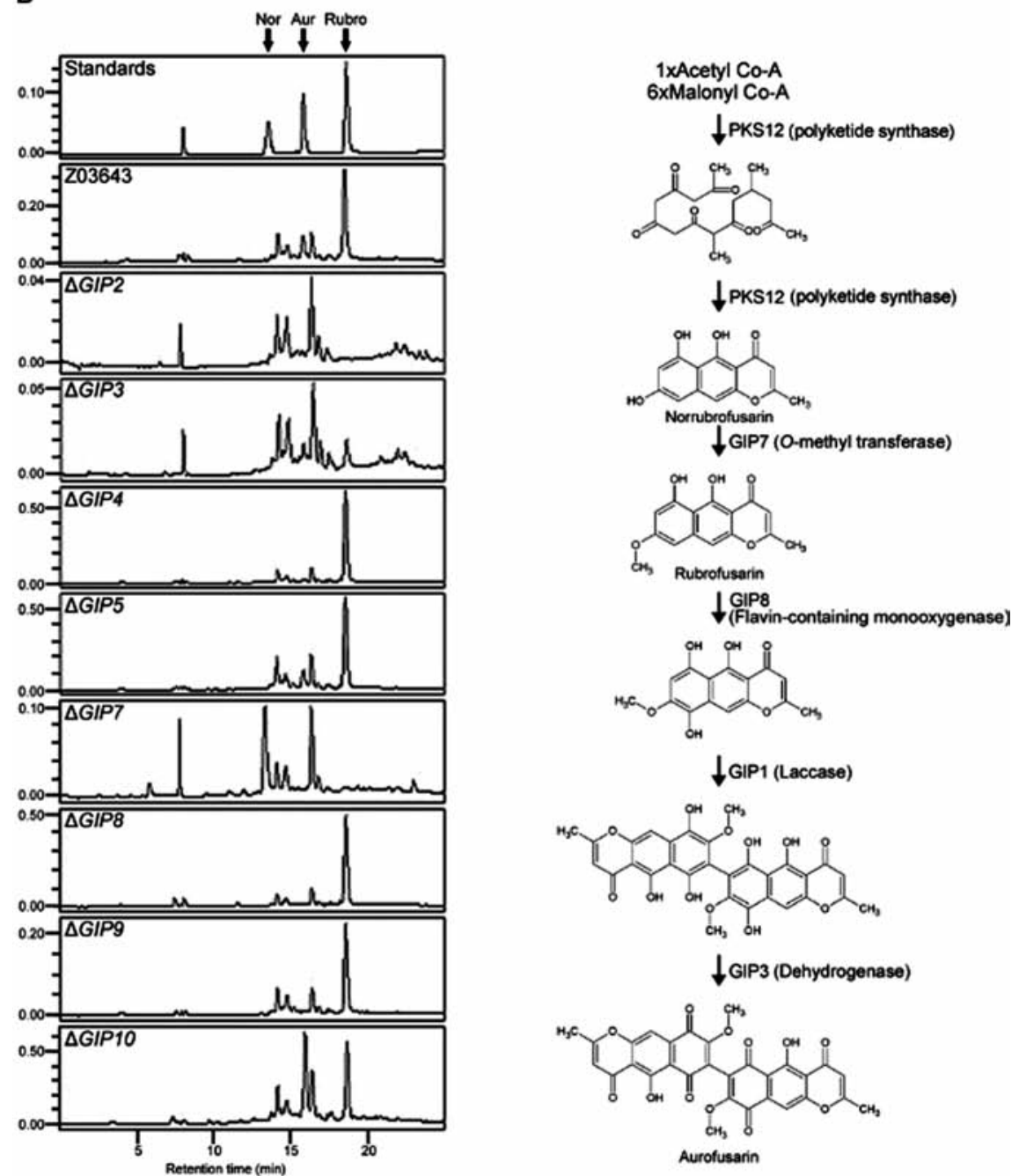

$\downarrow$ PKS12 (polyketide synthase)

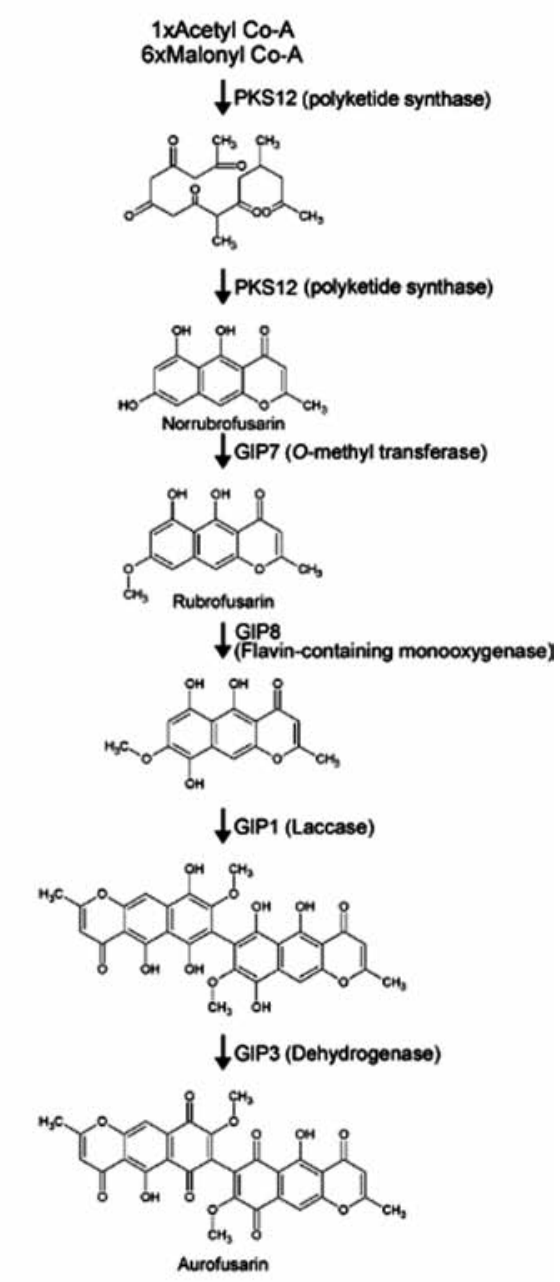

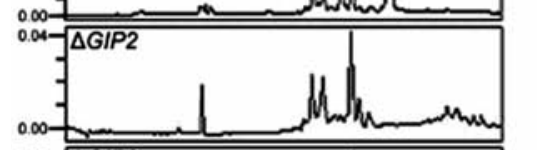
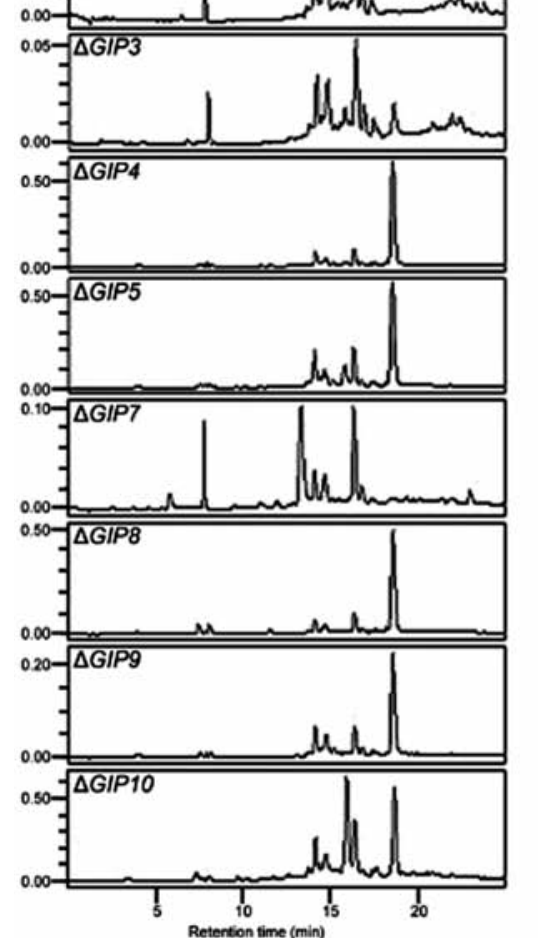

Fig. 7. Aurofusarin gene cluster and function of each gene in aurofusarin biosynthesis. (A) Molecular organization of the putative aurofusarin biosynthesis cluster in F. graminearum. This cluster was found in contig 1.116 from the $F$. graminearum genome databases. Numbers and arrows indicate possible ORFs and transcriptional directions, respectively. Nucleotide positions of the contig are indicated on the thick vertical bar. (B) HPLC chromatograms of pigments in F. graminearum wild-type and transgenic strains with the deletion of aurofusarin biosynthetic genes and the predicted pathway from the acetyl-CoA to aurofusarin in aurofusarin biosynthesis. The hydroxyl group of primary product produced by PKS12, nor-rubrofusarin, is converted to a methyl group by GIP7 resulting rubrofusarin. After oxidation by GIP8 and dimerization of monomers by GIP1, aurofusarin is synthesized as a result of the dehydrogenation by GIP3. The order of reactions by GIP 1, GIP 3 , and GIP 8 is not clear. Nor, nor-rubrofusarin; Aur, aurofusarin; Rubro, rubrofusarin. These data were in our previous reports ${ }^{47,48,50)}$ 
Korean government (MEST). And we thank Chang, I.-Y., Choi, G.J., Han, Y-K., Hong S.-Y., Jeon, J.J., Jin, J., Jung, S., Kang, H.-J., Kim, H., Kim, H.-S., Kim, J,-C., Kim J.-E., Kim, K.-H., Kim, Y.-T., Lee, H.-J., Lee, J., Lee, S., Lee, T., Lee, Y.-R., Leslie, J.F., Min, K., Myong, K., Oh, D.-W., Park, A.R., Park C., Park, K.-J., Ryu, J.-G. Seo, J.-A., Shim, W.-B., So, J., Sohn, H.-B., Yun S.-H. for their contributions to these studies.

\section{References}

1 ) Leslie, J.F. and Summerell, B.A.: The Fusarium laboratory manual (Ames, IA), (2006)

2 ) Desjardins, A.E. and Proctor, R.H.: Int. J. Food Microbiol., 119, 47-50 (2007)

3 ) Chung, H.-S.: Korean J. Mycol., 3, 31-36 (1975)

4 ) Kim, J.-C., Kang, H.-J., Lee, D.-H., Lee, Y.-W. and Yoshizawa, T.: Appl. Environ. Microbiol., 59 , 3798-3802 (1993)

5 ) Park, K.-J., Park, A.R. and Lee, Y.-W.: Food Addit. Contam., 9, 639 (1992)

6 ) Park, J.-C., Zong, M.-S. and Chang, I.-M.: Food Addit. Contam., 8, 447 (1991)

7 ) Park, K.-J. and Lee, Y.-W.: Proc. Jpn. Assoc. Mycotoxicol., 31, 37-41 (1990)

8 ) Lee, J., Chang, I.-Y., Kim, H., Yun, S.-H., Leslie, J.F. and Lee, Y.-W.: Appl. Environ. Microbiol., 75 , 3289-3295 (2009)

9 ) Lee, T., Lee, S.-H., Shin, J.Y., Yun, J.-C., Lee, Y.-W. and Ryu, J.-G.: J. Food Prot., 74, 1169-1174 (2011)

10) O’Donnell, K., Kistler, H.C., Tacke, B.K. and Casper, H.H.: Proc. Natl. Acad. Sci. USA, 97, 7905-7910 (2000)

11) Lee, Y.-W., Jeon, J.J., Kim, H., Jang, I.Y., Kim, H.-S., Yun, S.-H. and Kim, J.-G. in New horizons of mycotoxicology for assuring food safety. (ed. Yoshizawa, T) 117-122 (Japanese Association of Mycotoxicology, Kagawa, Japan; 2004).

12) Sohn, H.-B., Seo, J.-A. and Lee, Y.-W.: Food Addit. Contam., 16, 153-158 (1999)

13) Marasas, W.F.O., Nelson, P.E. and Toussoun, T.A.: Toxigenic Fusarium species. Identity and mycotoxicology (University Park, PA), (1984)

14) Ichinoe, M., Kurata, H., Sugiura, Y. and Ueno, Y.: Appl. Environ. Microbiol., 46, 1364-1369 (1983)

15) Tanaka, T., Hasegawa, A., Yamamoto, S., Lee, U.S., Sugiura, Y. and Ueno, Y.: J. Agric. Food Chem., 36, 979-983 (1988)

16) Yoshizawa, T. and Jin, Y.-Z.: Food Addit. Contam., 12, 689-694 (1995)

17) Ryu, J.-C., Ohtsubo, K., Izumiyama, N., Nakamura, K., Tanaka, T., Yamamura, H. and Ueno, Y.: Fund. Appl. Toxicol., 11, 38-47 (1988)

18) Alexander, N.J., McCormick, S.P., Waalwijk, C., van der Lee, T. and Proctor, R.H.: Fungal Genet. Biol., 48, 485-495 (2011)

19) Lee, T., Oh, D.-W., Kim, H.-S., Lee, J., Kim, Y.-H., Yun, S.-H. and Lee, Y.-W.: Appl. Environ. Microbiol., 67, 2966-2972 (2001)

20) Lee, T., Han, Y.-K., Kim, K.-H., Yun, S.-H. and Lee, Y.-W.: Appl. Environ. Microbiol., 68, 2148-2154 (2002)

21) Mirocha, C.J. and Christensen, C.M.: Annu. Rev. Phytopathol., 12, 303-330 (1974)

22) Massart, F., Meucci, V., Saggese, G. and Soldani, G.: J. Pediatr., 152, 690-695.e691 (2008)

23) Hagler, W.M. and Mirocha, C.J.: Appl. Environ. Microbiol., 39, 668-670 (1980) 
24) Richardson, K.E., Hagler, W.M., Jr and Hamilton, P.B.: Appl. Environ. Microbiol., 47, 1206-1209 (1984)

25) Hutchinson, C.R., Kennedy, J., Park, C., Kendrew, S., Auclair, K. and Vederas, J.: Antonie van Leeuwenhoek, 78, 287-295 (2000)

26) Cuomo, C.A., Guldener, U., Xu, J.-R., Trail, F., Turgeon, B.G., Di Pietro, A., Walton, J.D., Ma, L.-J., Baker, S.E., Rep, M., Adam, G., Antoniw, J., Baldwin, T., Calvo, S., Chang, Y.-L., DeCaprio, D., Gale, L.R., Gnerre, S., Goswami, R.S., Hammond-Kosack, K., Harris, L.J., Hilburn, K., Kennell, J.C., Kroken, S., Magnuson, J.K., Mannhaupt, G., Mauceli, E., Mewes, H.-W., Mitterbauer, R., Muehlbauer, G., Munsterkotter, M., Nelson, D., O’Donnell, K., Ouellet, T., Qi, W., Quesneville, H., Roncero, M.I.G., Seong, K.-Y., Tetko, I.V., Urban, M., Waalwijk, C., Ward, T.J., Yao, J., Birren, B.W. and Kistler, H.C.: Science, 317, 1400-1402 (2007)

27) Gaffoor, I., Brown, D.W., Plattner, R., Proctor, R.H., Qi, W. and Trail, F.: Eukaryot. Cell, 4, 1926-1933 (2005)

28） Kim, Y.-T., Lee, Y.-R., Jin, J., Han, K.-H., Kim, H., Kim, J.-C., Lee, T., Yun, S.-H. and Lee, Y.-W.: Mol. Microbiol., 58, 1102-1113 (2005)

29) Lee, S., Son, H., Lee, J., Lee, Y.-R. and Lee, Y.-W.: Curr. Genet., 57, 343-351 (2011)

30) Lee, J., Son, H., Lee, S., Park, A.R. and Lee, Y.-W.: Appl. Environ. Microbiol., 76, 3089-3096 (2010)

31) Lee, S., Son, H., Lee, J., Min, G., Choi, K.J., Kim, J.-C. and Lee, Y.-W.: Eukaryot. Cell, 10, 1043-1052 (2011)

32) Gray, J.S., Martin, G.C.J. and Rigby, W.: J. Chem. Soc., 1967(C), 2580-2587 (1967)

33) Tanaka, H. and Tamura, T.: Agric. Biol. Chem., 26, 767-770 (1962)

34) Dvorska, J.E., Surai, P.F., Speake, B.K. and Sparks, N.H.C.: Br. Poult. Sci., 42, 643-649 (2001)

35) Kotik, A.N. and Trufanova, V.A.: Mikol. Fitopatol., 32, 58-61 (1998)

36) Graham, J.G., Zhang, H., Pendland, S.L., Santarsiero, B.D., Mesecar, A.D., Cabieses, F. and Farnsworth, N.R.: J. Nat. Prod., 67, 225-227 (2004)

37) Kitanaka, S., Nakayama, T., Shibano, T. and Ohkoshi, E.: Chem. Pharm. Bull. (Tokyo), 46, 1650-1652 (1998)

38) Macias, M., Ulloa, M., Gamboa, A. and Mata, R.: J. Nat. Prod., 63, 757-761 (2000)

39） Kim, J.-E., Myong, K., Shim, W.-B., Yun, S.-H. and Lee, Y.-W.: Curr. Genet., 51, 99-108 (2007)

40) Han, Y.-K., Lee, T., Han, K.-H., Yun, S.-H. and Lee, Y.-W.: Curr. Genet., 46, 205-212 (2004)

41) Seo, B., Kim, H., Lee, Y. and Yun, S.: Plant Pathol. J., 23, 51 (2007)

42) Han, Y.-K., Kim, M.-D., Lee, S.-H., Yun, S.-H. and Lee, Y.-W.: Mol. Microbiol., 63, 768-779 (2007)

43) Kim, J.-E., Lee, H.-J., Lee, J., Kim, K.W., Yun, S.-H., Shim, W.-B. and Lee, Y.-W.: Curr. Genet., 55 , 449-459 (2009)

44) Hong, S.-Y., So, J., Lee, J., Min, K., Son, H., Park, C., Yun, S.-H. and Lee, Y.-W.: Fungal Genetics and Biology, 47, 364-372 (2010)

45) Min, K., Lee, J., Kim, J.-C., Kim, S.G., Kim, Y.H., Vogel, S., Trail, F. and Lee, Y.-W.: Eukaryot. Cell, 9, 1495-1503 (2010)

46) Son, H., Lee, J., Park, A.R. and Lee, Y.-W.: Fungal Genet. Biol., 48, 408-417 (2011)

47) Kim, J.-E., Han, K.-H., Jin, J., Kim, H., Kim, J.-C., Yun, S.-H. and Lee, Y.-W.: Appl Environ Microbiol, 71, 1701-1708 (2005)

48) Kim, J.-E., Jin, J., Kim, H., Kim, J.-C., Yun, S.-H. and Lee, Y.-W.: Appl. Environ. Microbiol., 72 , 
1645-1652 (2006)

49) Jung, S., Kim, J.-E., Yun, S.-H. and Lee, Y.-W.: J. Microbiol. Biotechnol., 16, 1392-1398 (2006)

50） Kim, J.-E., Kim, J.-C., Jin, J., Yun, S.-H. and Lee, Y.-W.: Plant Pathol. J., 24, 8-16 (2008)

51) Frandsen, R.J.N., Nielsen, N.J., Maolanon, N., Sørensen, J.C., Olsson, S., Nielsen, J. and Giese, H.: Mol. Microbiol., 61, 1069-1080 (2006)

52) Frandsen, R.J.N., Schütt, C., Lund, B.W., Staerk, D., Nielsen, J., Olsson, S. and Giese, H.: J. Biol. Chem., 286, 10419-10428 (2011) 